\title{
Language Learning Strategies of English for Specific Purposes Students at a Public University in Malaysia
}

\author{
Mohamed Ismail Ahamad Shah ${ }^{1}$, Yusof Ismail ${ }^{1}$, Zaleha Esa ${ }^{1} \&$ Ainon Jariah Muhamad ${ }^{1}$ \\ ${ }^{1}$ International Islamic University, Malaysia \\ Correspondence: Dr. Mohamed Ismail Ahamad Shah, English Language Department, International Islamic \\ University, Malaysia. E-mail: ismails@iium.edu.my
}

Received: August 22, 2012 Accepted: December 2, 2012 Online Published: December 25, 2012

doi:10.5539/elt.v6n1p153 URL: http://dx.doi.org/10.5539/elt.v6n1p153

\begin{abstract}
Studies on strategy research have shown the usefulness and importance of language learning strategies (LLS) for ESL and EFL learners. However, research on content-based learners in relation to English for Academic Purposes (EAP) and English for Occupational Purposes (EOP) has yet to be undertaken. This study, therefore, investigated the learning strategies of students at a public English medium university in Malaysia. The study was mainly motivated by concerns about the standards of English of graduates of Malaysian universities. These concerns have also been expressed by the university authorities. The purpose of the research was to investigate the patterns of LLS as reported by the students according to gender, courses, and undergraduate programmes. A total of 312 students from three degree programmes participated in this study. Their learning strategies were investigated based on the Strategy Inventory for Language Learning (SILL) (Oxford, 1990). The findings of the study indicated that the students from the different degree programmes differed in the use of LLS. However, there was no statistically significant relationship between LLS and gender.
\end{abstract}

Keywords: English for Academic Purposes (EAP), English for Occupational Purposes (EOP), Language Learning Strategies (LLS), Strategy Inventory for Language Learning (SILL), Content-based Language Learning, Learner-centred Course, Gender

\section{Introduction}

Language learning and teaching have evolved from a teacher-centred to a more student-centred approach and as a result the interest to find out how the students themselves learn a language has become a crucial area of study. As students are responsible for their own learning, looking at the strategies they adopt in language learning could give insights into the importance of the different strategies used, the extent to which they are used, and the factors that influence strategy use. This interest in LLS is evident based on a good number of valuable research on LLS in the different English as a Second Language (ESL) and English as a Foreign Language (EFL) contexts (e.g., Abdolmehdi Riazi, 2007; Kamarul Shukri Mat Teh, Mohamed Amin Embi, Nik Mohd Rahimi Nik Yusoff \& Zamri Mahamod, 2009; Abu Shmais, 2003; Li, 2005).

Research conducted on LLS have been much influenced by the development in cognitive psychology. LLS have been classified into metacognitive, cognitive and socioaffective strategies. Rubin (1987) viewed strategies in terms of processes and whether they contributed directly or indirectly to language learning. According to Oxford (1990a), LLS were the steps that language learners take to improve language learning and develop language competence. She divided the strategies into direct and indirect strategies which involved information, memory behaviours, knowledge of vocabulary, rules of grammar, thought and mental processes.

Though research to date has revealed that there is evidence of LLS being used by language learners, the frequency and variety of strategy use are dependent on a number of variables (Chamot \& Kupper, 1989). In general, there is a positive correlation between LLS and language proficiency. Research findings indicate effective use of particular types of strategies by good language learners (Chamot \& Kupper, 1989; O'Malley and Chamot, 1990; Oxford, 1993).

A comparison of strategy use by more proficient and less proficient learners seems to indicate that the former use a variety of strategies in many situations compared to the latter. This has been supported by Rossi-Le (1989) who found that proficient English language learners use self-management strategies such as planning, evaluation and 
formal practice more than the less proficient learners.

Good language learners possess abilities for successful language learning such as taking charge of their own learning, organising their language information, and creating their own opportunities to practice the language (Rubin \& Thompson, 1994). They also use linguistic knowledge and contextual cues in comprehension.

The primary objective in most of the research on LLS which began in the 1960s has been on discovering what good language learners do to learn a language. This was reflected in the particular importance given to the metacognitive strategies which include planning and directing or monitoring as found in Rossi-Le (1989).

Language proficiency is not the only factor that influences the selection and use of LLS by language learners. Many researchers have explored gender, for example, as a factor influencing LLS. Many of these studies on EFL have shown that females use strategies more frequently than males (Green, 1992; Noguchi, 1991; Green \& Oxford, 1993; Oxford, 1993). Besides gender, other factors that influence strategies are cultural backgrounds (Oxford \& Burry- Stock, 1995), learning styles (Sheorey, 1998; Oxford et. al, 1991) and learners' self-efficacy beliefs (Yang, Nae-Dong 1999). These factors have been suggested as factors influencing language strategy use (Oxford \& Burry-Stock, 1995).

Li (2005) looked at gender in relation to the LLS. Li's findings suggest that generally Chinese students used fewer and low frequency strategies. This implies that the students changed the strategy use according to the change in the language environment. In addition, Abdolmehdi Riazi (2007) conducted a study in another EFL context to find out overall strategy use of 120 female Arabic-speaking students. He found that higher level students use the LLS more automatically and faster, and that lower level students use more of compensation strategies. Participants in general, however, tend to use metacognitive, cognitive, and compensation strategies more than social, affective, and memory strategies. Abdolmehdi Riazi also concluded that their overall use of LLS is not much different from other cultural groups.

Studies in the Malaysian context have also supported the relationship between LLS and language performance. A study by Mohamed Amin Embi, Juriah Long, Mohd Isa Hamzah (2001), indicated a significant positive relationship between LLS use and language performance. The high achievers reported greater strategy use than the low achievers.

Relationships between LLS and motivation have also been revealed in Kamarul Shukri et al. (2009). They found that language learners with higher levels of motivation possess a richer repertoire of strategies and employ them more frequently. Their study showed that there was significant gender difference in LLS as females have a higher tendency to use overall LLS than males. A significant difference between genders also surfaced in the use of affective and metacognitive strategies with females using the LLS more often than males. LLS are considered as indicators of how good language learners deal with the problems they encounter in the language learning process. This study will not only give English teachers valuable information on how their students process information, but also how to plan and select the appropriate strategies.

Studies on strategy research (Li, 2005; Mohamed Amin et al., 2001; Chamot \& Kupper, 1989; Rubin \& Thompsons, 1994) have shown the usefulness and importance of LLS for ESL and EFL learners. LLS could be equally important for learners of English for Specific Purposes (ESP) who may be taking EAP and EOP courses. However, research on these groups of learners appears not to have been undertaken. There is also a need to investigate strategy use among students in different programmes as these differences may affect choice of strategies.

\section{Methodology}

\subsection{Objectives of the Study}

The purpose of the research was to investigate the patterns of LLS as reported by the students according to gender, courses, and their undergraduate programmes. In particular, the study addresses the following research questions:

1) What are the language learning strategies of university students?

2) Is there a difference in the use of language learning strategies between male and female students?

3) Is there a difference in the use of language learning strategies between students pursuing English for Academic Purposes and English for Occupational Purposes courses?

4) Is there a difference in the use of language learning strategies among students majoring in Engineering, English and Economics? 
The respondents of the study were 312 Malay-speaking undergraduates at a public English-medium university in Malaysia. They were students from the faculties of Economics and Management taking English for Occupational Purposes (EOP), Human Sciences (English majors) taking English for Academic Purposes (EAP) and Engineering taking English for Occupational Purposes (EOP). In addition, they have also met the English language requirements by achieving the required band of 6 in the University Proficiency Test, equivalent to band 6 in IELTS, or 550 in TOEFL.

\subsection{Instrument}

This study employed LLS of Oxford's (1990) Strategy Inventory for Language Learning (SILL). The instrument specifies six learning strategies represented by a number of statements each with a corresponding Likert scale between 1 and 5. Scale 1 represents "Never or almost never true of me," 2 "Usually not true of me," 3 "Somewhat true of me", 4 "Usually true of me" and 5 "Always or almost always true of me." Learning styles 1 comprises 9 items; 2, 14 items; 3, 6 items; 4, 9 items; 5, 6 items; and 6, 6 items. The score for each item under a learning strategy is added up and average obtained. The higher the average score, the higher the propensity of the strategy being used by the respondents.

The SILL has 50 items which are divided into direct and indirect strategies. Direct strategies are further divided into Memory strategies (9 items), Cognitive strategies (14 items), and Compensation strategies (6 items). The indirect strategies are divided into Metacognitive strategies (9 items), Affective strategies (6 items), and Social strategies (6 items). The description of the strategies areas is as follows:

- Memory strategies are used for entering new information into memory storage and for retrieving it when needed for communication.

- Cognitive strategies are used for linking new information with existing schemata and for analysing and classifying it.

- $\quad$ Compensation strategies include such strategies as guessing and using gestures. Such strategies are needed to fill any gaps in the knowledge of the language.

- Metacognitive strategies are techniques used for organizing, planning, focusing and evaluating one's own learning.

- $\quad$ Affective strategies are used for handling feelings, attitudes and motivations.

- $\quad$ Social strategies are used for facilitating interaction by asking questions, and cooperating with others in the learning process

Oxford (1990) suggests the minimum and maximum ranges for high, medium and low strategy users. High, Medium and Low strategy users are those whose scores range are from 3.5-5, 2.5-3.4 and 1.0-2.4 respectively. Studies by Oxford and Burry-Stock (1995) and Oxford (1996) have produced high Cronbach alpha indexes (between 0.91 and 0.94 ) in studies across different cultures. SILL has also been validated in many studies (Oxford \& Burry-Stock, 1995). The index of Cronbach alpha obtained for this study was .914. SILL has also proven to have concurrent and predictive validity when the results of SILL are related to variables such as proficiency, motivation and learning styles (Oxford and Burry-Stock, 1995 and Oxford, 1996).

The EAP course is a learner-centred course designed for learners to conduct library research in order to produce an academic argumentative faculty-related research paper. The EOP course, on the other hand, is designed to equip students with the necessary English language skills for occupational purposes. Students participate in an extended work-related simulation while receiving the necessary skills-based training to enable them to fulfill the various communication needs at the workplace.

\section{Findings}

Table 1 describes the demographic profile of the respondents. Of the 312 respondents, 86 (27.6\%) were males while $226(72.4 \%)$ were females. They have been exposed to learning English for at least 11 years prior to joining the university. Female respondents outnumbered their male counterpart (72.4\% vs. $27.6 \%)$. 
Table 1. Demographics $(\mathrm{N}=312)$

\begin{tabular}{lcc}
\hline & Frequency & Percent \\
\hline Gender & & \\
\hline Male & 86 & 27.6 \\
\hline Female & 226 & 72.4 \\
\hline Total & 312 & 100.0 \\
\hline Course & & \\
\hline EOP: LE4600(Econs \& Mgmt) & 139 & 44.5 \\
\hline EOP: LE4100(Engineering) & 51 & 16.4 \\
\hline EAP: LE4000(English ) & 122 & 39.1 \\
\hline Total & 312 & 100.0 \\
\hline
\end{tabular}

Malaysians made up $95.8 \%$ of the respondents, and generally spoke their mother tongue Malay at home (95.5\%). Among Malaysian respondents $69.1 \%$ spoke mainly Malay, whereas $30.9 \%$ conversed in both Malay and English at home. All of the respondents consider English proficiency as important (14.4\%) and very important (85.6\%). Almost all respondents (97.4\%) enjoy learning English. Only the minority said their oral (4.5\%) and writing $(5.2 \%)$ proficiency is poor. It is also the minority who said that their oral and writing proficiencies are excellent, i.e. $5.5 \%$ and $4.9 \%$ respectively.

\subsection{Research Question 1: What Are the Learning Strategies of University Students?}

The pattern of learning strategies is identified based on overall means (Table 2). The higher the mean, the higher the rank. The learning strategy with the highest mean is ranked the first in the categories. The learning strategy with the lowest mean is ranked the lowest in the categories. The means of the learnning strategies are presented in descending order.

These learning strategies are Social, Compensation, Cognitive, Affective, Metacognitive, and Memory. Grand means range from 3.15 to 3.82. Memory learning showed that the strategy was the lowest (3.15), whereas Social learning strategy is the highest (3.82). Results show that the student sample preferred learning strategies in the following order: Social, Compensation, Cognitive, Affective, Metacognitive, and Memory. One can easily observe that Social, Compensation, and Cognitive obtained higher means which commensurate with matching frequencies. These learning strategies are subscribed by many students, thus carrying more meaningful means compared to Affective and Metacognitive, for instance, with only five and seven responses, respectively.

The findings of the study indicate that the highest mean score was social learning strategy $(\mathrm{M}=3.82 ; \mathrm{SD}=.579$ ) followed by compensation learning strategy. The results indicate that the students perceived themselves as using the social learning strategy.

Table 2. Mean scores of Learning Strategies

\begin{tabular}{|c|c|c|c|c|c|}
\hline $\begin{array}{l}\text { Learning } \\
\text { Category }\end{array}$ & Strategy & Rank & $\mathrm{N}$ & Mean & Std. Deviation \\
\hline Social & & $1 \mathrm{st}$ & 121 & 3.82 - high & .579 \\
\hline Compensation & & 2nd & 80 & $3.60-$ high & .599 \\
\hline Cognitive & & $3 \mathrm{rd}$ & 31 & 3.56 - high & .496 \\
\hline Affective & & 4th & 5 & 3.53 - high & .653 \\
\hline Metacognitive & & 5 th & 7 & $3.20-$ medium & .605 \\
\hline Memory & & 6th & 22 & 3.15 - medium & .685 \\
\hline
\end{tabular}

\subsection{Research Question 2: Are There Differences in Learning Strategies between Male and Female Students?}

Statistical results (Table 3) reveal that there was no overall significant relationship between gender and learning strategies. However, when t-test was applied on the survey data, results show that gender provides a good explanation for different learning strategies preferred by male and female students. These marked differences emerge for learning strategies - Social $(p=.021)$, Memory $(p=.000)$, and Affective $(p=.003)$. Male and female students exhibit varying levels for each of the three learning strategies. For Social, male use of the strategy is lower (3.70) than that of female (3.87). Male students' preference for Memory is much lower (2.89) compared to their female counterparts (3.25). For Affective, male also show lower rating of 3.35 compared to 3.59 for female. 
As far as the learning strategies are concerned, the female students had a higher mean score compared to the male students. For example, the mean score for the Metacognitive learning strategy for female students was $\mathrm{M}=3.24$ and male students $\mathrm{M}=3.11$, followed by cognitive learning strategies. There was also a significant difference in the learning strategies used by the male and female students in terms of Social learning strategy $(\mathrm{p}=.021)$, Memory learning strategy $(\mathrm{p}=.00)$ and Afective strategy $(\mathrm{p}=.003)$.

Table 3. T-test Results of Learning Strategies by Gender

\begin{tabular}{lllllll}
\hline $\begin{array}{l}\text { Learning } \\
\text { strategy }\end{array}$ & Gender & $\mathrm{N}$ & Mean & Std. Deviation & $\begin{array}{l}\text { Std. Error } \\
\text { Mean }\end{array}$ & Significance \\
\hline Metacognitive & Male & 86 & 3.11 & .658 & .071 & $\mathrm{NS}$ \\
\cline { 2 - 7 } & Female & 226 & 3.24 & .582 & .039 & $\mathrm{NS}$ \\
\hline \multirow{2}{*}{ Cognitive } & Male & 86 & 3.48 & .513 & .055 & $\mathrm{NS}$ \\
\cline { 2 - 7 } & Female & 226 & 3.60 & .487 & .032 & $\mathrm{NS}$ \\
\hline \multirow{2}{*}{ Compensation } & Male & 86 & 3.55 & .653 & .070 & $\mathrm{NS}$ \\
\cline { 2 - 7 } & Female & 226 & 3.62 & .578 & .038 & $\mathrm{NS}$ \\
\hline Social & Male & 86 & 3.70 & .604 & .065 & $* \mathrm{p}=.021$ \\
\cline { 2 - 7 } & Female & 226 & 3.87 & .564 & .038 & $\mathrm{p}=.021$ \\
\hline \multirow{2}{*}{ Affective } & Male & 86 & 2.89 & .685 & .074 & $\mathrm{p}=.000$ \\
\cline { 2 - 7 } & Female & 226 & 3.25 & .660 & .044 & $\mathrm{p}=.000$ \\
\cline { 2 - 7 } & Male & 86 & 3.35 & .710 & .077 & $\mathrm{p}=.003$ \\
\hline
\end{tabular}

$\mathrm{NS}=$ Not significant $-{ }^{*} \mathrm{p}<0.05$

\subsection{Research Question 3: Are There Differences in Learning Strategies Used by Students Pursuing English for} Academic Purposes (EAP) and English for Occupational Purposes (EOP)?

There were $44.5 \%$ of the students studying English for Occupational Purposes for Economics students, $16.4 \%$ studying English for Occupational Purposes for Engineering students, and 39.1\% studying English for Academic Purposes. ANOVA results show that students pursuing these courses adopted different learning strategies (See table 4). These differences are statistically significant $(\mathrm{p}=.000)$.

Table 4. ANOVA Learning Strategies between English Courses

\begin{tabular}{llllll}
\hline & Sum of & & & \\
& Squares & Df & Mean Square & F & Sig. \\
\hline Between Groups & 468.524 & 2 & 234.262 & 939.184 & .000 \\
Within Groups & 70.340 & 282 & .249 & & \\
Total & 538.863 & 284 & & & \\
\hline
\end{tabular}

$\mathrm{N}=312$

In order to find out the intensity of usage of various learning strategies by students in the three courses, the strategies were ranked according to grand means, and this produced the resulting Table 5. All learning strategies (5 out of 6) ranked first in English for Academic Purposes, second in English for Occupational Purposes for Economics students (5 out of 6), and third in English for Occupational Purposes for Engineering students (5 out of 6). Although all students from the three English courses used all the six learning strategies, there were differences in their preferences.

The students' preferences for learning strategies use are reflected in the ranking presented in table 5. However, there were differences in their preferences for individual learning strategies. For English for Academic Purposes, the students used metacognitive, cognitive, social, memory and affective strategies most. This is indicated as number one in the ranking. However, the use of compensation strategies was ranked second. English for Occupational Purposes for Economics students also used all of the strategies as students in English for Academic Purposes but to a lesser extent. Thus, they were ranked second, except for compensation strategies for which 
they were ranked third. English for Occupational Purposes for Engineering students, on the other hand, used compensation strategies most and were ranked first. However, their use of all the other strategies ranked third indicating that their use of those strategies was the least preferred.

Table 5. Ranking of Learning Strategies in Three English Courses

\begin{tabular}{|c|c|c|c|c|c|c|}
\hline English courses & Metacognitive & Cognitive & Compensation & Social & Memory & Affective \\
\hline $\begin{array}{l}\text { LE4600 } \\
\text { (EOP for Econs \& } \\
\text { Mngmt) } \\
\mathrm{N}=139\end{array}$ & thencosing & 2 & e & 2 & 2 & 2 \\
\hline $\begin{array}{l}\text { LE4100 } \\
\text { (EOP for Engin) } \\
\mathrm{N}=51\end{array}$ & 3 & 3 & 1 & 3 & 3 & 3 \\
\hline $\begin{array}{l}\text { LE4000 } \\
\text { (English for } \\
\text { Academic Purposes } \\
\text { for all students) } \\
\mathrm{N}=122\end{array}$ & 1 & 1 & 2 & 1 & 1 & 1 \\
\hline
\end{tabular}

3.4 Research Question 4: Are There Differences in Learning Strategies between Students Pursuing the Different Degree Programmes?

Learning strategies adopted by students were also reflected by their affiliation to respective degree programmes. Three student groups belong to English, Engineering and Economics faculties, respectively. ANOVA results (see Table 6) reveal significant differences for five out of six learning strategies with the exception of the compensation strategy. P-values for the statistical significance vary from .005 to .000 . This means that despite using the six available learning strategies, students in each degree programme applied varying levels of intensity of usage.

Table 6. ANOVA Learning Strategies by Majors (English, Engineering and Economics Majors)

\begin{tabular}{|c|c|c|c|c|c|c|}
\hline & & $\begin{array}{l}\text { Sum of } \\
\text { Squares }\end{array}$ & Df & Mean Square & $\mathrm{F}$ & Sig. \\
\hline \multirow[t]{3}{*}{ Metacognitive } & Between Groups & 4.919 & 2 & 2.459 & 6.952 & .001 \\
\hline & Within Groups & 99.761 & 282 & .354 & & \\
\hline & Total & 104.680 & 284 & & & \\
\hline \multirow[t]{3}{*}{ Cognitive } & Between Groups & 3.947 & 2 & 1.973 & 8.410 & .000 \\
\hline & Within Groups & 66.173 & 282 & .235 & & \\
\hline & Total & 70.120 & 284 & & & \\
\hline \multirow[t]{3}{*}{ Compensatory } & Between Groups & .146 & 2 & .073 & .199 & .819 \\
\hline & Within Groups & 103.382 & 282 & .367 & & \\
\hline & Total & 103.528 & 284 & & & \\
\hline \multirow[t]{3}{*}{ Social } & Between Groups & 9.985 & 2 & 4.993 & 16.165 & .000 \\
\hline & Within Groups & 87.097 & 282 & .309 & & \\
\hline & Total & 97.083 & 284 & & & \\
\hline \multirow[t]{3}{*}{ Memory } & Between Groups & 5.019 & 2 & 2.509 & 5.458 & .005 \\
\hline & Within Groups & 129.656 & 282 & .460 & & \\
\hline & Total & 134.675 & 284 & & & \\
\hline \multirow[t]{3}{*}{ Affective } & Between Groups & 9.578 & 2 & 4.789 & 12.222 & .000 \\
\hline & Within Groups & 110.494 & 282 & .392 & & \\
\hline & Total & 120.072 & 284 & & & \\
\hline
\end{tabular}


There are no statistically significant differences ( $>$ >.05) in learning strategies among three majors (i.e. English, Engineering, and Economics) (see Table 7). In other words, students in the three undergraduate programmes use more or less the same learning strategies in learning the three English courses. Learning strategies, therefore, are not dependent on students' academic majors. Students tend to choose the strategies apparently to enhance their learning.

Table 7. ANOVA Learning Strategies by Three Degree Programmes (English, Engineering, and Economics)

\begin{tabular}{llllll}
\hline & Sum of & & & \\
& Squares & Df & Mean Square & F & Sig. \\
\hline Between Groups & 7.534 & 2 & 3.767 & 2.405 & .093 \\
Within Groups & 349.285 & 223 & 1.566 & & \\
Total & 356.819 & 225 & & & \\
\hline
\end{tabular}

\section{Discussion}

The findings of the study showed the following learning strategy ranking of LLS: Social, Compensation, Cognitive, Affective, Metacognitive and Memory. The higher the mean score, the higher would be the tendency for the respondents to use the strategy. Studies conducted in other university contexts (Goh and Kwah, 1997; Bremner, 1999; Klassen, 1994; Yang, 1994; Abdolmehdi Riazi, 2007) generally show results consistent with the present study in so far as the compensation and memory strategies are concerned.

Goh and Kwah's (1997) survey on the strategy use of tertiary-level students from the People's Republic of China (PRC) learning English as a Second Language in Singapore, reported metacognitive and compensation strategies to be the most frequently used, whereas memory strategies the least used. Although compensation emerged as the second most frequently-used strategy, metacognitive, however, ranked the second last in our study. Bremner's (1999) study of students at the City University of Hong Kong indicated that compensation and metacognitive strategies were the most-frequently used whereas affective and memory strategies were the least used. Klassen's (1994) survey on the strategy use of university students learning English in Taiwan found compensation strategies being used the most and memory strategies the least. Similar results were also reported by Yang (1994) on a study on university students learning English in Taiwan with compensation strategies most frequently used.

Our study did not reflect exactly those exhibited by the sample used by Abdolmehdi Riazi (2007). His study revealed this pattern: metacognitive, cognitive, and compensation strategies then social, memory and affective strategies. Based on our review of the literature, it is clear that compensation strategy generally emerged as the most frequently-used strategy while memory is the least-frequently used strategy.

The spread (i.e. minimum-maximum ranges) in our survey data was too broad (i.e., 1.89-5.00, the statistics are not included in the study) that we could not classify the results meaningfully into high, medium and low strategy users as recommended by Oxford (1990). It may be feasible to discern the three types of uses (i.e. high, medium and low) with a larger sample.

Results do generally support that female students tend to use higher level of the learning strategies compared to their male counterpart. The means shown by females were higher than those by male students (Table 3 ). This study establishes support for the findings of Noguchi (1991); Green (1992); Oxford, (1993) and Green \& Oxford (1993) and Kamarul Shukri et al. (2009). It is also interesting to note that Kamarul Shukriet al. 's (2009) study, unlike the other studies cited on English Language learning, looked at the relationship between gender and the strategies used in learning Arabic.

The results also show that learning strategies are associated with English courses studied, namely, EAP, EOP for Engineering students and EOP for Economics and Management Science students. Students used principally all of the learning strategies in descending order of priority (see Table 5) for EAP, followed by EOP for Economics and Management Science students and lastly, EOP for Engineering students. As mentioned previously, EOP courses are taken by students from both the faculties of Economics and Management Science and Engineering. EAP in this study however, is taken by students majoring in English. Therefore, it is not surprising that the course tops the list in the array of strategies used.

It is interesting to note that students in the sample confirmed that their adoption of learning strategies seemed to be shaped by the curriculum of their respective degree programmes, except for the compensation strategy. If the three degree programmes may be placed on a continuum of verbal to non-verbal, the English majors may be placed at the extreme left, Economics in the middle, and Engineering at the other extreme. 


\section{Conclusion}

Findings of this study indicate that students from the three different degree programmes differed in the use of the six learning strategies. Next, gender appears to be important for social, memory and affective learning strategies. Thirdly, learning strategies also appear to be related to the three English for Specific Purposes (ESP) courses, namely, English for Academic Purposes for all students, English for Occupational Purposes for Economics and Management Science students and English for Occupational Purposes for Engineering students. The relationship found between the learning strategies and the ESP courses could very well be due to the different demands of the three courses. It can also be concluded that the degree programmes, to a certain extent, tend to shape the learning strategies of the respective students.

One of the pedagogical implications that can be drawn from the findings of this study is that instructors have a role in exposing students to a variety of strategies thereby giving students the opportunities to choose strategies that best suit their learning objectives and learning styles. In addition to facilitating learning through the various strategies in the classroom instructors can also incorporate the use of strategies in the materials and the classroom activities. The instructors can guide the students in the systematic use of strategies which will enable them to learn language more effectively.

The findings of this study also showed that not all students are familiar with the repertoire of strategies that are available at their disposal. Therefore, the instructors' role in familiarizing them with the strategies becomes paramount. This calls for the importance of some kind of strategy training in the context of the EFL/ESL syllabus. The study was limited to only three degree programmes. It did not include other programmes whose students might have exhibited learning strategies different from those shown by the subjects of this study. In addition to questionnaires future research could include interviews which may potentially furnish us with more in-depth information. Personal interviews could also give further insights into similarities of strategies of both gender.

\section{References}

Abdolmehdi Riazi. (2007). Foreign Language Annals, 40(3), 433-440. http://dx.doi.org/10.1111/j.1944-9720.2007.tb02868.x

Abu Shmais, W. (2003). Language learning strategy use in Palestine. TESL-EJ, 7(2), 20-33.

Chamot, A. U., \& Kupper, L. (1989). Learning strategies in foreign language instruction. Foreign Language Annals, 22, 13-24. http://dx.doi.org/10.1111/j.1944-9720.1989.tb03138.x

Green, J. M. (1992). Additional analyses of Puerto Rican Strategy data. Unpublished manuscript, University of Puerto Rico at Mayaguez.

Green, J., \& Oxford, R. (1993). A closer look at learning strategies, L2 Proficiency, and gender. TESOL Quarterly, 29, 261-297. http://dx.doi.org/10.2307/3587625

Kamarul Shukri Mat Teh, Mohamed Amin Embi, Nik Mohd Rahimi Nik Yusoff, \& Zamri Mahamod. (2009). A closer look at gender and Arabic LLS use. European Journal of Social Sciences, 9(3), 399-407.

Klassen, J. M. (1994). The LLS of freshman English students in Taiwan: A case study. Paper presented at the Third International Symposium and Book Fair on English Teaching, Taipei, Taiwan.

Li, Aiqun. (2005). A Look at Chinese ESL Students' Use of Learning Strategies in Relation to their English Language Proficiency, Gender and Perceived Language Difficulties - A Quantitative Study, Supporting Independent English Language Learning in the 21 st Century: Proceedings of the Independent Learning Association Conference Inaugural - 2005.

Mohamed Amin Embi, Juriah Long, \& Mohd Isa Hamzah. (2001). Language learning strategies employed by secondary school students in Malaysia. Jurnal Pendidikan, 26, 3-20.

Noguchi, T. (1991). Questionnaire for learners. Tottori University, Tottori, Japan.

O'Malley, J. M., \& Chamot, A. (1990). Learning Strategies in Second Language Acquisition. Cambridge: Cambridge University Press. http://dx.doi.org/10.1017/CBO9781139524490

Oxford, R. L. (1990a). LLS: What Every Teacher Should Know. Boston, MA: Heinle \& Heinle.

Oxford, R. L. (1993). Instructional implications of gender differences in language learning styles andstrategies. Applied Language Learning, 4, 65-94.

Oxford, R. L., \& Burry-Stock, Judith A. (1995). Assessing the use of language learning strategies worldwide with 
the ESL/EFL version of the strategy inventory for language learning (SILL). University of Alabama, Tuscaloosa, AL, USA.

Oxford, R., L., Eherman, M. E., \& Lavine, R. Z. (1991). Style wars: Teacher-student style conflicts in the language classroom. In S. S. Magnan (Ed), Challenges in the 1990s for College Foreign Language Programs (pp. 1-25). Boston: Heinle \& Heinle.

Oxford R. L., \& Green, (1996). Language learning histories: Learners and teachers helping each other understand learning styles and strategies. TESOL Journal, 6(1), 20-23.

Rossi-Le, L. (1989). Perceptual learning style preferences and their relationship to language learning strategies in adult students of English as a second language. Unpublished doctoral dissertation, Drake University, Des Moines, IA.

Rubin, J. (1987). Learner strategies: Theoretical Assumptions, Research History and Typology. Englewood Cliffs, NJ: Prentice Hall.

Rubin, J., \& Thompsons I. (1994) How to be a more successful language learner (2nd ed.). Boston: Heinle \& Heinle.

Sheorey, R. (1998). The state of English and English language teaching in India. TESOL Matters, 8(4), 1, 19.

Yang, Nae-Dong. (1999). The relationship between EFL learners' beliefs and learning strategy use. Department of foreign languages and literature, National Taiwan University, Taipei, Taiwan, ROC. 